\title{
Determination and Characteristic Analysis of Atmospheric Carbonyl Compounds in a North China Plain Hub City
}

\author{
Jinhe Wang', 2*, Chongxu Zhang ${ }^{1}$, Zhuobiao $\mathrm{Ma}^{3}$, Bo Lv ${ }^{4}$, Kai Zhang ${ }^{5 * *}$ \\ ${ }^{1}$ School of Municipal and Environmental Engineering, Co-Innovation Center for Green Building of Shandong Province, \\ Key Laboratory of Renewable Energy Utilization Technologies in Building of Ministry of Education, \\ Shandong Jianzhu University, Jinan, China \\ ${ }^{2}$ Shanghai Key Laboratory of Atmospheric Particle Pollution and Prevention (LAP3), Fudan University, Shanghai, China \\ ${ }^{3}$ Research Center for Eco-Environmental Sciences, Chinese Academy of Sciences, Beijing, China \\ ${ }^{4}$ Jinan Academy of Environmental Sciences, Jinan, China \\ ${ }^{5}$ State Key Laboratory of Environmental Criteria and Risk Assessment, Chinese Research Academy \\ of Environmental Sciences, Beijing, China
}

Received: 25 August 2018

Accepted: 15 December 2018

\begin{abstract}
The concentration and variation trend of atmospheric carbonyl compounds in Jinan were first measured during autumn 2017 for three continuous weeks at a 3-h time resolution. A total of 14 types of carbonyls were identified, among which acetone, formaldehyde, and acetaldehyde were the most abundant carbonyls and their concentrations were $3.75 \pm 2.21$ ppbv, $2.65 \pm 1.67$ ppbv, $1.83 \pm 1.17$ ppbv, respectively; formaldehyde and acetaldehyde showed similar diurnal variation trends. Butyraldehyde and isovaleraldehyde were another two important carbonyl compounds with concentrations of $1.05 \pm 0.59 \mathrm{ppbv}$ and $1.04 \pm 0.47 \mathrm{ppbv}$, respectively. The average $\mathrm{C} 1 / \mathrm{C} 2$ ratio was 1.90 , which indicated that anthropogenic sources were the main contributor of atmospheric carbonyls. The correlation analysis showed that the measured carbonyls had different sources. Formaldehyde, acetaldehyde, butyraldehyde and isovaleraldehyde were the most important $\mathrm{OVOC}$ contributors to $\cdot \mathrm{OH}$ reactivity and $\mathrm{O}_{3}$ formation.
\end{abstract}

Keywords: carbonyl compounds, variation trend, $\cdot \mathrm{OH}$ reactivity, ozone formation, North China Plain

\section{Introduction}

Carbonyl compounds, including aldehydes and ketones, are a group of oxygenated volatile organic

*e-mail: jhw@sdjzu.edu.cn

**e-mail: zhangkai@craes.org.cn compounds (OVOCs) in the atmosphere and play an important role in atmospheric photochemical reactions [1]. Carbonyls are important precursors for generating hydroxyl radical $(\cdot \mathrm{OH})$, peroxyacetyl nitrate $(\mathrm{PAN})$ and ozone $\left(\mathrm{O}_{3}\right)$ [2]. Moreover, the photochemical reactions of carbonyl compounds can produce low-volatility organic compounds (LVOCs) which can condense or adsorb onto particle surface or absorb into pre-existing particulate matter to facilitate the formation of secondary organic 
aerosols (SOAs). These secondary processes seriously affect the whole tropospheric atmospheric oxidation tendency $[3,4]$. The sources of carbonyl compounds are divided into primary emissions and secondary formation; primary sources include vehicle exhaust emissions, industrial emissions, biomass burning and plant emissions, while secondary formation is mainly due to photochemical reactions [2,5]. Carbonyl compounds have a direct negative effect on human health, and formaldehyde has already been classified as a human carcinogen by the International Agency for Research on Cancer (IARC) [6], which can lead to severe cancers like nasopharyngeal cancer. In addition, acetaldehyde has also been listed as a suspected human carcinogen [7].

Because of the negative environmental and health effects, carbonyl compounds have been of wide concern [8-11], Jiang et al. [12] studied the concentration levels and variations of carbonyl compounds in Orléans, France (a semi-urban site), while Wang et al. [2] analyzed the source of carbonyl compounds in a rural area of the Yangtze River Delta. At present, most domestic studies in China have focused on the Yangtze River Delta, Pearl River Delta and Beijing City. Jinan, the capital city of Shandong Province (among the top three provinces of China in terms of economic volume), is a regional hub city characterized by advanced manufacturing and chemical industries, and is located in the heartland of the North China Plain (NCP). Jinan is one of the most polluted cities in China in terms of air pollution and also a major city in the air pollution transmission channel for the Jing-Jin-Ji Metropolitan Region (Beijing City-Tianjin City-Hebei Province, the largest urbanized region in China, even in the world), due to its rapid industrial development and heavy traffic volume. Strict policy and measures have been conducted in recent years by central and local governments to control atmospheric particle pollution in Jing-Jin-Ji and the greater NCP region, including Jinan City, and have subsequently achieved good results, which led to a decreasing trend of particle concentrations in the atmosphere. However, the atmospheric ozone concentration showed an obvious ongoing rising trend during the same period, which was closely linked to increasing concentrations of VOCs in the atmosphere - especially atmospheric carbonyls (OVOCs). At present, more and more attention has been given to VOC measurement and ozone control in NCP regional hub cities like Jinan City. Although Zhang et al. [13] and Liu et al. [14] studied the pollution characteristics of typical non-methane hydrocarbons (NMHCs) in Jinan, no literatures has reported atmospheric carbonyl compounds in Jinan. Even in other large cities of the NCP region there are still very few studies on atmospheric carbonyls - especially for long-term measurement with high temporal resolution. Therefore, it is of significant importance to study the pollution characteristics, sources and photochemical reactivities of atmospheric carbonyl compounds in Jinan for a longer period with higher time resolution. This study presented the concentration level and variation trends of atmospheric carbonyls in Jinan in autumn 2017 at a higher time resolution of 3 hours for 3 continuous

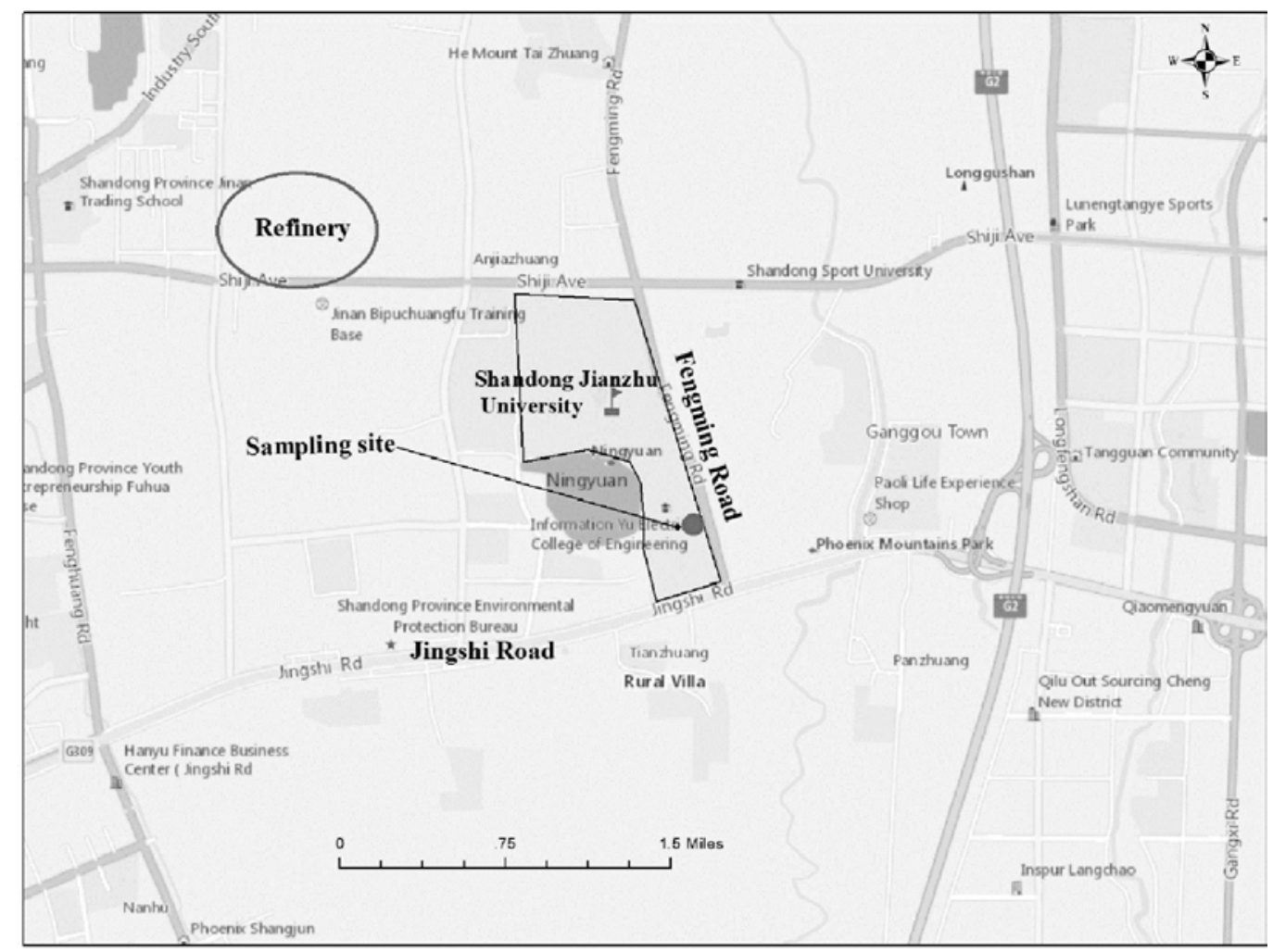

Fig. 1. Location of sampling site in Jinan. 
weeks, then analyzed their possible sources and determined their photochemical reactivities from aspects of $\mathrm{OH}$ reactivity and $\mathrm{O}_{3}$ formation. The findings will help to further understand the atmospheric pollution status in NCP region in terms of OVOC pollution and $\mathrm{O}_{3}$ control, and thus contribute to relevant research field and environmental protection policy formulation as well.

\section{Material and Methods}

Sampling Site and Time

The sampling site was on the roof of a six-storey classroom building (approximately $20 \mathrm{~m}$ above the ground) on the campus of Shandong Jianzhu University (E 117.19, N 36.68) in eastern urban Jinan (Fig. 1; the official air quality monitoring station affiliated with Shandong Provincial Department of Environmental Protection is also located on the same roof). The campus where the sampling site located is close to Jingshi Road (a 10-lane main road) on the south side and adjacent to Fengming Road (an eight-lane main road) on the east side, so the traffic is heavy - especially during rush hours. The campus is rich in vegetation, and the surroundings are mainly residential areas except for a large oil refinery $2 \mathrm{~km}$ to the northwest. The measurement campaign was conducted from September $7^{\text {th }}$ to $29^{\text {th }}, 2017$.

\section{Sampling Methods and Analysis}

The sampling and analysis of atmospheric carbonyls were strictly in accordance with the EPA Method TO-11A [15]. The air samples were collected by 2,4-dinitrophenylhydrazine (DNPH)-coated cartridges with a front-set ozone scrubber to eliminate $\mathrm{O}_{3}$ interference. Every day from 7:00 to 22:00, each sample was collected every three hours with sampling flow of $0.8 \mathrm{~L} / \mathrm{min}$, and one sample with flow of $0.2 \mathrm{~L} / \mathrm{min}$ was collected during the night for eight hours (22:00-6:00). Meanwhile, one laboratory blank and one field blank were collected each day and a total of 176 samples were obtained for the campaign. Samples were sealed and stored at $4^{\circ} \mathrm{C}$ in a refrigerator, and then analyzed by HPLC. The UV detector has a wavelength of $360 \mathrm{~nm}$. Separation column was Inertsil ODS-P C18 column $(5 \mu \mathrm{m}, 4.6 \times 250 \mathrm{~mm})$. Gradient elution was used, and the mobile phase was water and acetonitrile. The types of carbonyls were determined at concentration range of $0.02-1.50 \mu \mathrm{g} / \mathrm{ml}$, covering the actual concentration range of carbonyl compounds in the atmosphere.

\section{Results and Discussion}

Weather Conditions and Air Quality Parameters

During the campaign, the concentrations of $\mathrm{SO}_{2}$, $\mathrm{CO}, \mathrm{NO}_{2}, \mathrm{O}_{3}$ and $\mathrm{PM}_{2.5}$ were also collected by online monitoring instruments (Thermo Series) at the sampling site. The meteorological parameters (temperature, relative humidity, wind speed, wind direction and pressure) were measured by automatic weather station. The average temperature was $23.5 \pm 3.9^{\circ} \mathrm{C}$ (range: $15.0-38^{\circ} \mathrm{C}$ ), and the average atmospheric pressure was $1025.62 \pm 2.42 \mathrm{hPa}$. The remaining parameters are shown in Fig. 2.

\section{Concentrations of Atmospheric Carbonyls}

14 types of carbonyls were identified in the ambient air of Jinan, and their mean concentrations were listed in Table 1, including formaldehyde, acetaldehyde, acetone, butyraldehyde, benzaldehyde,

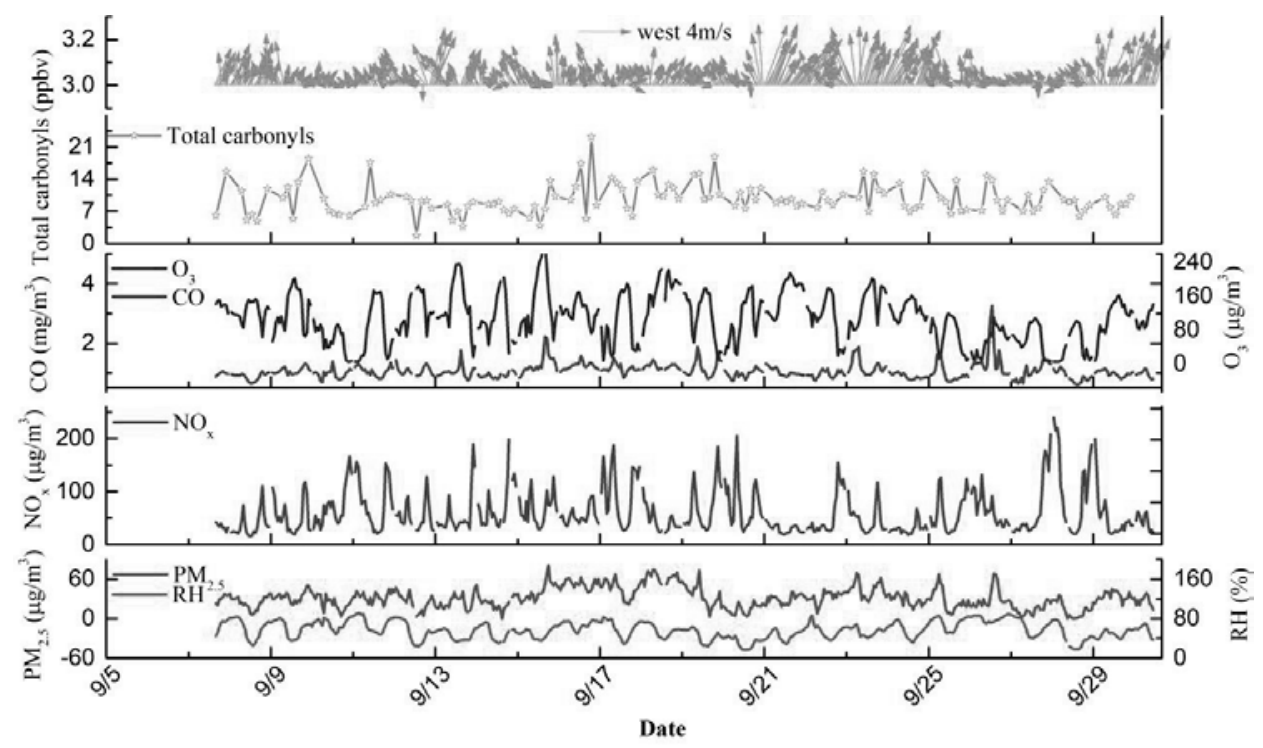

Fig. 2. Time series of total carbonyls, related gases, particles and meteorological parameters in Jinan from 7 to 29 Sept. 2017. 
Table 1. Concentrations and photochemical properties of the measured carbonyls in Jinan.

\begin{tabular}{|c|c|c|c|c|c|}
\hline Compound & $\begin{array}{c}\text { Mean } \pm \text { SD } \\
(\mathrm{ppbv})\end{array}$ & $\begin{array}{c}\text { MIR } \\
\left(\mathrm{g} \mathrm{O}_{3} / \mathrm{g} \text { VOCs }\right) \\
\end{array}$ & $\begin{array}{c}\mathrm{K}^{\mathrm{OH} *} 10^{12} \\
\left(\mathrm{~cm}^{3} /(\text { molecule } \cdot \mathrm{s})\right)\end{array}$ & $\begin{array}{c}\text { OFP } \\
\left(\mu g \cdot m^{-3}\right)\end{array}$ & $\begin{array}{l}\mathrm{L}_{\mathrm{OH}} \\
\left(\mathrm{s}^{-1}\right) \\
\end{array}$ \\
\hline Formaldehyde & $2.65 \pm 1.67$ & 9.46 & 9.37 & 30.74 & 0.61 \\
\hline Acetaldehyde & $1.83 \pm 1.17$ & 6.54 & 15.00 & 20.74 & 0.65 \\
\hline Acetone & $3.75 \pm 2.21$ & 0.36 & 0.17 & 3.14 & 0.02 \\
\hline Butyraldehyde & $1.05 \pm 0.59$ & 5.28 & 24.00 & 16.17 & 0.62 \\
\hline Isovaleraldehyde & $1.04 \pm 0.47$ & 4.42 & 27.00 & 16.09 & 0.69 \\
\hline Propionaldehyde & $0.46 \pm 0.26$ & 7.08 & 20.00 & 7.78 & 0.23 \\
\hline o-Tolualdehyde & $0.26 \pm 0.14$ & - & 18.00 & - & 0.11 \\
\hline Valeraldehyde & $0.27 \pm 0.13$ & 4.42 & 28.00 & 4.18 & 0.19 \\
\hline Hexaldehyde & $0.19 \pm 0.11$ & 3.79 & 9.58 & 2.88 & 0.04 \\
\hline Crotonaldehyde & $0.16 \pm 0.08$ & - & - & - & - \\
\hline Benzaldehyde & $0.11 \pm 0.06$ & -0.57 & 12.00 & -0.27 & 0.03 \\
\hline m-Tolualdehyde & $0.08 \pm 0.04$ & - & 17.00 & - & 0.03 \\
\hline 2,4-Dimethylbenzaldehyde & $0.06 \pm 0.04$ & - & - & - & - \\
\hline Acrolein & $0.05 \pm 0.02$ & 7.45 & - & 0.93 & - \\
\hline Total & $9.72 \pm 3.56$ & - & - & - & - \\
\hline
\end{tabular}

Note: " - " means there are no available rates for this compound.

"SD" means standard deviation.

o-tolualdehyde, hexaldehyde, 2,4-dimethylbenzaldehyde, propionaldehyde, valeraldehyde, isovaleraldehyde, m-tolualde, crotonaldehyde and acrolein. Acrolein and o-tolualdehyde were detected in only 5 samples, and crotonaldehyde was detected in 11 samples. The total concentration of carbonyl compounds was $9.72 \pm 3.56 \mathrm{ppb}$, in which acetone is the most abundant species $(3.75 \pm 2.21$ ppbv), which contributed $31.3 \%$ of total carbonyls (Fig. 3), followed by formaldehyde at $2.65 \pm 1.67 \mathrm{ppbv}$, acetaldehyde is the third-ranked abundant species with concentration of $1.83 \pm 1.17 \mathrm{ppbv}$, and formaldehyde and acetaldehyde accounted for $22.17 \%$ and $15.32 \%$ of total measured carbonyls, respectively. Acetone, formaldehyde and acetaldehyde collectively accounted for $68.79 \%$ of total ambient carbonyls, which were consistent with previous studies [16]. One of the reasons for the higher concentration of acetone in the atmosphere was the much longer lifetime before it was removed by photolysis (about 60 days) and $\mathrm{OH}$ reaction (about 53 days), meanwhile, formaldehyde has a lifetime of 1.2 days due to reaction with $\mathrm{OH}$ radicals and 4 hours by photolysis and acetaldehyde has a lifetime of $8.8 \mathrm{~h}$ due to reaction with $\mathrm{OH}$ radicals and 6 days by photolysis [1, 17]. Acetone, therefore, stays in the atmosphere much longer than formaldehyde and acetaldehyde, which makes it the most abundant species of the measured OVOCs.

It is noteworthy that both the concentration of butyraldehyde $(1.05 \pm 0.59 \mathrm{ppbv})$ and isovaleraldehyde
$(1.04 \pm 0.47 \mathrm{ppbv})$ were very high compared with the other remaining nine carbonyls, accounting for $8.77 \%$ and $8.66 \%$ of total carbonyls, respectively. However, the remaining nine types of carbonyl compounds only accounted for $13.78 \%$ of the total measured carbonyls. Butyraldehyde is mainly produced by photochemical oxidation of n-butene, while isovaleraldehyde is primarily produced from the chemical degradation of 3-methyl-1-butene [18], and they all are used to serve as raw materials for organic synthesis. Butyraldehyde, n-butene, isovaleraldehyde and 3-methyl-1-butene

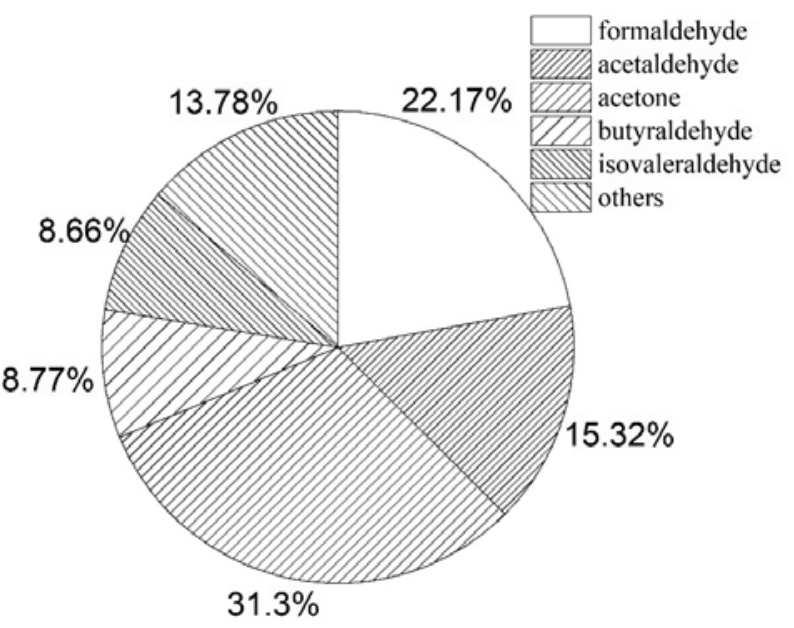

Fig. 3. Compositions of measured carbonyl compounds in Jinan. 
Table 2. Comparison of major carbonyls with other sites (unit: $\mu \mathrm{g} \cdot \mathrm{m}^{-3}$ ).

\begin{tabular}{|c|c|c|c|c|c|c|c|}
\hline \multicolumn{2}{|c|}{ Sites } & Type of site & Formaldehyde & Acetaldehyde & Acetone & Period & Ref. \\
\hline \multicolumn{2}{|c|}{ Jinan } & Urban & 3.25 & 3.17 & 8.37 & Sep. 2017 & This study \\
\hline \multirow{2}{*}{\multicolumn{2}{|c|}{ Beijing }} & \multirow{2}{*}{ Urban } & 5.9 & 6.6 & 13.1 & autumn 2008 & \multirow{2}{*}[26]{} \\
\hline & & & 8.3 & 9.8 & 22.1 & autumn 2009 & \\
\hline \multicolumn{2}{|c|}{ Shanghai } & Urban & 6.82 & 8.24 & 9.64 & Oct. 2007 & [27] \\
\hline \multicolumn{2}{|c|}{ Guangzhou } & Urban & 4.78 & 7.09 & 8.48 & autumn 2005 & [28] \\
\hline \multicolumn{2}{|c|}{ Guiyang } & Urban & 4.8 & 5.7 & 5.1 & Dec. 2008-Aug. 2009 & {$[25]$} \\
\hline \multirow{2}{*}{ Hong Kong } & TW & Urban & 3.55 & 3.95 & - & \multirow{2}{*}{ Sep.-Oct. 2010} & \multirow{2}{*}[20]{} \\
\hline & TMS & Mountain & 3.31 & 2.51 & - & & \\
\hline \multicolumn{2}{|c|}{ Orléans, France } & Semi-urban & 2.79 & 1.19 & 5.28 & Oct. 2010 & [12] \\
\hline \multicolumn{2}{|c|}{ Madrid, Spain } & Forest park & 0.64 & 1.01 & 2.11 & Oct. 2010 & [21] \\
\hline \multicolumn{2}{|c|}{ Yantai } & Coastal city & 1.43 & 2.33 & - & Jan. 2011 & [22] \\
\hline \multicolumn{2}{|c|}{ Qinzhou } & Coastal city & 3.00 & 2.96 & 1.94 & Oct. 2011 & {$[23]$} \\
\hline \multicolumn{2}{|c|}{ Longmen } & Rural & 2.40 & 2.46 & 2.13 & Aug. 2012-Jan. 2013 & [24] \\
\hline
\end{tabular}

Note: TW:Tsuen Wan; TMS: Mt. Tai Mo Shan; “ _ ” means there are no available concentrations.

have short lifetimes of 9.6 hours, 7.37 hours, 8.3 hours, and 7.3 hours, respectively, due to fast reaction with $\cdot \mathrm{OH}$ radicals, assuming the average ambient $\cdot \mathrm{OH}$ concentration at $\sim 1.2 \times 10^{6}$ molecules $\mathrm{cm}^{-3}$. Therefore, the high concentrations of butyraldehyde and isovaleraldehyde may be due to the presence of local emission sources, such as the large refinery in the vicinity of the sampling site, which produces more than 50 kinds of chemical products, including gasoline, kerosene, diesel, liquefied petroleum gas, light oil, etc.

Table 2 listed the concentrations of formaldehyde, acetaldehyde and acetone in Jinan and other sites. The unit has been converted from $\mathrm{ppbv}$ to $\mu \mathrm{g} \cdot \mathrm{m}^{-3}$ since no molar concentrations were expressed in the reference papers [19]. The concentrations of formaldehyde and acetaldehyde in Jinan were comparable with that in Hong Kong [20], but higher than that in foreign cities (in Spain and France) [12, 21]. It was also higher than coastal cities such as Qinzhou and Yantai [22, 23] of China. The concentration of acetone in Jinan is higher than that in rural and forest areas [24], especially in the similar mountainous area of Guiyang [25]. Compared with mega cities affected by photochemical smog processes, such as Beijing, Shanghai and Guangzhou [26-28], the concentration levels of formaldehyde and acetaldehyde in Jinan were much lower.

\section{Diurnal Variation of Atmospheric Carbonyls}

Fig. 4 showed diurnal variations of major atmospheric carbonyls in Jinan. Accounting for $68.79 \%$ of the total measured carbonyl compounds, acetone, formaldehyde and acetaldehyde are the main object of research. The diurnal variation trends of formaldehyde and acetaldehyde were similar. The first peak of these two kinds of aldehydes appeared in the morning (7:00-10:00), then formaldehyde and acetaldehyde reached their second peak in the afternoon (16:0019:00), suggesting that motor vehicle exhaust during rush hours in the morning and evening contributed to the peak of formaldehyde and acetaldehyde besides other contributions from photo-oxidation of VOCs. Interestingly, formaldehyde and acetaldehyde's minimum values appeared in the afternoon (13:0016:00). These two aldehydes could be produced by photochemical oxidation reactions [29, 30], and could also act as photochemical reaction reactants [1] to initiate photolysis and $\mathrm{OH}$ radical reactions; both the

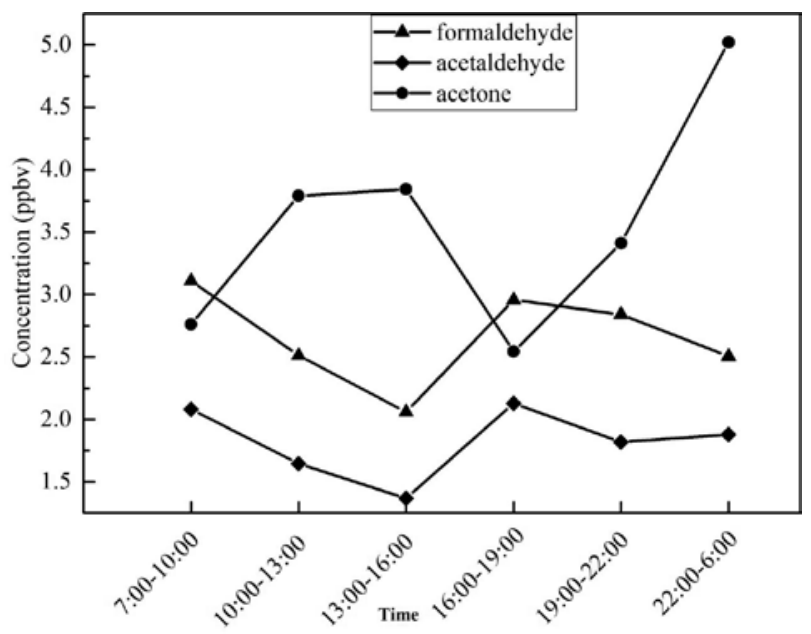

Fig. 4. Mean diurnal cycle of formaldehyde, acetaldehyde and acetone in Jinan in autumn. 
solar radiation intensity and atmospheric temperature were higher during the sampling time at noon of September in Jinan, which could speed up the photolysis and $\cdot \mathrm{OH}$ radical reactions of aldehydes and subsequently result in the lower concentration of formaldehyde and acetaldehyde at noon. However, acetone showed peak and continuous high levels during night, and there was only one sample at night (sampling for 6 hours), which meant the time for mass release or formation of acetone could not be exactly determined for this sampling period. During night, solar radiation disappeared but vehicle and industrial emissions persisted, which may cause the concentration of relatively stable carbonyl compounds such as acetone, remaining at higher level, and moreover the lowering atmospheric boundary layer may also help to maintain or increase the concentration of carbonyl compounds during nighttime [26]. The high concentration of acetone during noon may be due to higher ambient temperature during that period, which facilitates the acetone-like organic solvent to evaporate into atmosphere during the production process of the nearby large oil refinery to the northwest.

\section{Concentration Ratios and Correlation Analysis}

The molar ratios of formaldehyde/acetaldehyde $(\mathrm{Cl}$ / C2) were determined in 10 sites (Table 3) from literature. The $\mathrm{C} 1 / \mathrm{C} 2$ ratio has been widely adopted as an indicator to diagnose the possible sources of formaldehyde. The ratio was 1 2 for urban areas and $\sim 10$ for forested areas[8]. A higher $\mathrm{C} 1 / \mathrm{C} 2$ ratio implies that the photooxidation of natural hydrocarbons such as isoprene yields more formaldehyde than acetaldehyde [31]. In the present study, the average $\mathrm{C} 1 / \mathrm{C} 2$ ratio was 1.90 , higher than that in island (1.36) [32], and was similar to that (1.79) in Shanghai [27] and Beijing (1.59) [33], but lower than that in Orléans (2.44) [12], Hong Kong (UST)
(2.86) [34], and forested regions (Cibola National Forest, U.S. and Zhangjiajie, China) [11, 35], implying that anthropogenic sources are the main source of carbonyl compounds in the eastern part of urban Jinan.

In order to further investigate sources of carbonyl compounds at the sampling site, Table 4 lists the correlation coefficients between 11 types of carbonyl compounds, finding that the correlation of formaldehyde with most of the remaining carbonyl compounds was low, especially for formaldehyde with acetone, which may be due to the source complexity of carbonyl compounds. For example, formaldehyde not only originates from vehicle emissions, but also can be produced by photooxidation of VOCs; in contrast, acetone was mainly emitted from solvents used in chemical industries, and its atmospheric lifetime was also much longer than other carbonyls. Good correction coefficients between acetaldehyde, propionaldehyde, butyraldehyde and hexaldehyde possibly indicated that they were mainly from emissions of vehicular exhaust because there are two main roads adjacent to the sampling site and the traffic volume is very high.

\section{Photochemical Reaction Activity}

Carbonyl compounds are important intermediates of atmospheric photochemical reactions and play an important role in the photochemical smog process, especially for ozone formation. The contribution of different carbonyl compound to photochemical reactions mainly depends on its photochemical activity. In order to evaluate their contributions to photochemical reactions and ozone formation made by different carbonyls, calculations of $\cdot \mathrm{OH}$ consumption rate $\left(L_{O H}\right)$ and ozone formation potential $(O F P)$ were performed on the measured carbonyl compounds. $L_{O H}$ of VOC species is defined by:

Table 3. Comparison of formaldehyde/acetaldehyde concentration ratios in Jinan and other sites.

\begin{tabular}{|c|c|c|c|c|}
\hline Location & Type & C1/C2 (ppbv/ppbv) & Period & Reference \\
\hline Orléans, France & Semi-urban & 2.44 & Oct. 2010-Jul. 2011 & {$[12]$} \\
\hline Mount Tai & Mountain & 2.74 & Summer 2014 & {$[18]$} \\
\hline Cibola National Forest, U.S. & Forested & 2.3 & Summer 1997 & {$[11]$} \\
\hline Zhangjiajie & Forested & 6.67 & Sep.-Nov. 2014 & {$[35]$} \\
\hline Hong Kong (UST) & Background & 2.86 & Nov. 2011 & {$[34]$} \\
\hline Carmen, Mexico & Island & 1.36 & Autumn 2004 & {$[32]$} \\
\hline Guangzhou & Urban & 1.23 & Nov.-Dec. 2005 & {$[10]$} \\
\hline Nanning & Urban & 0.70 & Oct. 2011-Jul. 2012 & {$[16]$} \\
\hline Shanghai & Urban & 1.79 & Jul.-Oct. 2008 & {$[27]$} \\
\hline Beijing & Urban & 1.59 & Sep. 2017 & This study \\
\hline Jinan & Urban & 1.90 & & \\
\hline
\end{tabular}

Note: UST: Hong Kong University of Science and Technology. 
Table 4. Correlations of carbonyl compounds in the ambient air of Jinan city.

\begin{tabular}{|c|c|c|c|c|c|c|c|c|c|c|c|}
\hline Compounds & 1 & 2 & 3 & 4 & 5 & 6 & 7 & 8 & 9 & 10 & 11 \\
\hline Formaldehyde (1) & 1 & & & & & & & & & \\
\hline Acetaldehyde (2) & $0.310^{* *}$ & 1 & & & & & & & & \\
\hline Acetone (3) & -0.050 & -0.094 & 1 & & & & & & & & \\
\hline Propionaldehyde (4) & 0.244 & $0.757^{* *}$ & $0.377^{* *}$ & 1 & & & & & & & \\
\hline Butyraldehyde (5) & 0.047 & $0.519^{* *}$ & $0.397^{*}$ & $0.473^{* *}$ & 1 & & & & & & \\
\hline Valeraldehyde (6) & 0.138 & -0.048 & $0.437^{*}$ & 0.512 & 0.319 & 1 & & & & & \\
\hline Isovaleraldehyde (7) & -0.070 & 0.072 & 0.076 & 0.273 & 0.150 & -0.466 & 1 & & & & \\
\hline Hexaldehyde (8) & $0.301^{* *}$ & $0.666^{* *}$ & $0.259^{* *}$ & $0.327^{*}$ & $0.608^{* *}$ & -0.044 & 0.030 & 1 & & & \\
\hline Benzaldehyde (9) & $-0.320^{*}$ & $-0.366^{* *}$ & 0.213 & -0.273 & $0.288^{*}$ & 0.415 & -0.075 & -0.178 & 1 & & \\
\hline 2,4-dimethylbenzaldehyde (10) & -0.146 & $-0.297^{* *}$ & 0.043 & $-0.303^{*}$ & -0.087 & 0.061 & -0.282 & -0.136 & $0.581^{* *}$ & 1 & \\
\hline o-tolualdehyde (11) & $-0.196^{*}$ & 0.011 & $0.315^{* *}$ & $0.302^{*}$ & $0.492^{* *}$ & 0.253 & 0.193 & 0.050 & $0.283^{*}$ & 0.161 & 1 \\
\hline
\end{tabular}

Note: ** Correlation is significant at the 0.01 level (2-tailed).

* Correlation is significant at the 0.05 level (2-tailed).

$$
L_{\mathrm{OH}}=[\mathrm{VOC}]_{i} \times K_{i}^{\mathrm{OH}}
$$

...where $[V O C]_{i}$ is the molecule concentration of VOC species $i$ (molecule $/ \mathrm{cm}^{3}$ ) and $K_{i}^{O H}$ denotes the rate constant (unit: $\mathrm{cm}^{3} /($ molecule $\cdot \mathrm{s})$ ) of $[\mathrm{VOC}]_{i}$ reacting with hydroxyl radicals at $298 \mathrm{~K}$ with values from Atkinson's work [36, 37]. The following equation was used to calculate the contribution to $\mathrm{O}_{3}$ formation by individual carbonyl:

$$
O F P=[V O C]_{i} \times M I R i
$$

...where MIRi coefficients were taken from Carter [3840]. Table 1 summarized $O F P$ and $L_{O H}$ of atmospheric carbonyl compounds in the sampling site of Jinan. Isovaleraldehyde, acetaldehyde, butyraldehyde and formaldehyde played major roles in $\cdot \mathrm{OH}$ removal, together accounting for $80 \%$ of the total $\cdot \mathrm{OH}$ removal by carbonyls, while the $L_{O H}$ of other measured carbonyls were much lower (some of which can even be negligible). Formaldehyde, acetaldehyde, butyraldehyde, isovaleraldehyde and propionaldehyde were the top five species that contributed $89 \%$ to the total ozone formation potentials. The $O F P$ value of benzaldehyde was negative $\left(-0.27 \mu \mathrm{g} \cdot \mathrm{m}^{-3}\right)$, which meant it had negative effects on the generation of ozone. Based on the above analysis, formaldehyde, acetaldehyde, butyraldehyde and isovaleraldehyde were four key active species among the measured carbonyl compounds in Jinan in terms of photochemical reaction activity. In addition, the role of propionaldehyde cannot be ignored due to its relatively high $L_{O H}$ and $O F P$, which were lower than those of the four key carbonyls mentioned above but still much higher than those of the remaining 9 kinds of carbonyls.

\section{Conclusions}

Fourteen types of carbonyl compounds, including formaldehyde, acetaldehyde, acetone, butyraldehyde, benzaldehyde, o-tolualdehyde, hexaldehyde, 2,4-dimethylbenzaldehyde, propionaldehyde, valeraldehyde, isovaleraldehyde, m-tolualdehyde, crotonaldehyde and acrolein, were first measured in Jinan, China, in September 2017 for three continuous weeks at a high time resolution of 3 hours. Acetone, formaldehyde and acetaldehyde were determined to be the three most abundant carbonyls, accounting for $68.79 \%$ of total measured carbonyls. Diurnal variations suggested that vehicle emissions were an important contributor to some major aldehydes. The $\mathrm{C} 1 / \mathrm{C} 2$ ratio indicated that anthropogenic sources were the main source of carbonyl compounds in the eastern urban area of Jinan. The correlation coefficients between carbonyl compounds were low, implying that they had different sources. Among all the measured carbonyls, formaldehyde, acetaldehyde, butyraldehyde and isovaleraldehyde not only played an important role in the $\cdot \mathrm{OH}$ reactions, but also made a major contribution to ozone formation.

\section{Acknowledgements}

This work was funded by the Natural Science Foundation of China (Nos. 41305124, 41205093), the Opening Project of Shanghai Key Laboratory of Atmospheric Particle Pollution and Prevention (No. FDLAP18005) and the National Key Research \& Development Program of the Ministry of Science and Technology of China (No. 2016YFE0112200). We also thank the Co-Innovation Center for Green Building 
of Shandong Province, the Key Laboratory of Renewable Energy Utilization Technologies in the Building of Ministry of Education (No. X18027Z) and the Jinan Academy of Environmental Sciences for their great support.

\section{Conflict of Interest}

The authors declare no conflict of interest.

\section{References}

1. ATKINSON R. Atmospheric chemistry of VOCs and NOx. Atmospheric Environment, 34 (12-14), 2063, 2000.

2. WANG M., CHEN W.T., SHAO M., LU S.H., ZENG L.M., HU M. Investigation of carbonyl compound sources at a rural site in the Yangtze River Delta region of China. Journal of Environmental Sciences, 28, 128, 2015.

3. LU K.D., ROHRER F., HOLLAND F., FUCHS H., BOHN B., BRAUERS T., CHANG C.C., HASELER R., HU M., KITA K., KONDO Y., LI X., LOU S.R., NEHR S., SHAO M., ZENG L.M., WAHNER A., ZHANG Y.H., HOFZUMAHAUS A. Observation and modelling of $\mathrm{OH}$ and $\mathrm{HO}_{2}$ concentrations in the Pearl River Delta 2006: a missing $\mathrm{OH}$ source in a VOC rich atmosphere. Atmospheric Chemistry and Physics, 12 (3), 1541, 2012.

4. RYERSON T.B., TRAINER M., HOLLOWAY J.S., PARRISH D.D., HUEY L.G., SUEPER D.T., FROST G.J., DONNELLY S.G., SCHAUFFLER S., ATLAS E.L., KUSTER W.C., GOLDAN P.D., HUBLER G., MEAGHER J.F., FEHSENFELD F.C. Observations of ozone formation in power plant plumes and implications for ozone control strategies. Science, 292 (5517), 719, 2001.

5. KIM K.H., HONG Y.J., PAL R., JEON E.C., KOO Y.S., SUNWOO Y. Investigation of carbonyl compounds in air from various industrial emission sources. Chemosphere, 70 (5), 807, 2008.

6. IARC. Monographs on the evaluation of carcinogenic risks to humans. 2004.

7. LUI K.H., DAI W.T., CHAN C.S., TIAN L., NING B.F., ZHOU Y., SONG X., WANG B., LI J., CAO J.J., LEE S.C., HO K.F. Cancer risk from gaseous carbonyl compounds in indoor environment generated from household coal combustion in Xuanwei, China. Environmental Science and Pollution Research, 24 (21), 17500, 2017.

8. PANG X.B., MU Y.J. Seasonal and diurnal variations of carbonyl compounds in Beijing ambient air. Atmospheric Environment, 40 (33), 6313, 2006.

9. MU Y.J., PANG X.B., QUAN J.N., ZHANG X.S. Atmospheric carbonyl compounds in Chinese background area: A remote mountain of the Qinghai-Tibetan Plateau. Journal of Geophysical Research, 112, D22302, 2007.

10. LUE H.X., CAI Q.Y., WEN S., Chi Y.G., GUO S.J., SHENG G.Y., FU J.M., ANTIZAR-LADISLAO B. Carbonyl compounds in the ambient air of hazy days and clear days in Guangzhou, China. Atmospheric Research, 94 (3), 363, 2009.

11. VILLANUEVA-FIERRO I., POPP C.J., MARTIN R.S. Biogenic emissions and ambient concentrations of hydrocarbons, carbonyl compounds and organic acids from ponderosa pine and cottonwood trees at rural and forested sites in Central New Mexico. Atmospheric Environment, 38 (2), 249, 2004.

12. JIANG Z.H., GROSSELIN B., DAELE V., MELLOUKI A., MU Y.J. Seasonal, diurnal and nocturnal variations of carbonyl compounds in the semi-urban environment of Orléans, France. Journal of Environmental Sciences, 40, 84, 2016.

13. ZHANG G.Q., WANG N., JIANG X.J., ZHAO Y. Characterization of ambient volatile organic compounds (VOCs) in the area adjacent to a petroleum refinery in Jinan, China. Aerosol and Air Quality Research, 17 (4), 944, 2017.

14. LIU Z.C., LI N., WANG N. Characterization and source identification of ambient VOCs in Jinan, China. Air Quality Atmosphere and Health, 9 (3), 285, 2015.

15. USEPA. Compendium of Methods for the Determination of Toxic Organic Compounds in Ambient Air Second Edition: Compendium Method TO-11A Determination of Formaldehyde in Ambient Air Using Adsorbent Cartridge Followed by High Performance Liquid Chromatography (HPLC). (Active Sampling Methodology). 1999.

16. GUO S.J., CHEN M., TAN J.H. Seasonal and diurnal characteristics of atmospheric carbonyls in Nanning, China. Atmospheric Research, 169, 46, 2016.

17. DAI W.T., HO S.S.H., HO K.F., LIU W.D., CAO J.J., LEE S.C. Seasonal and diurnal variations of mono- and dicarbonyls in Xi'an, China. Atmospheric Research, 113, 102,2012

18. YANG X., XUE L.K., YAO L., LI Q.Y., WEN L., ZHU Y.H., CHEN T.S., WANG X.F., YANG L.X., WANG T., LEE S.C., CHEN J.M., WANG W.X. Carbonyl compounds at Mount Tai in the North China Plain: Characteristics, sources, and effects on ozone formation. Atmospheric Research, 196, 53, 2017.

19. SEINFELD J.H., PANDIS S.N. Atmospheric Chemistry and Physics: From Air Pollution to Climate Change $\left(3^{\text {rd }}\right.$ Edition). New York: John Wiley \& Sons, 2016.

20. LING Z.H., GUO H., CHEN G.X., LAM S.H.M., FAN S.H.M. Formaldehyde and acetaldehyde at different elevations in mountainous areas in Hong Kong. Aerosol and Air Quality Research, 16 (8), 1868, 2016.

21. VILLANUEVA F., TAPIA A., NOTARIO A., ALBALADEJO J., MART NEZ E. Ambient levels and temporal trends of VOCs, including carbonyl compounds, and ozone at Cabañeros National Park border, Spain. Atmospheric Environment, 85, 256, 2014.

22. HO K.F., HO S.S.H., HUANG R.J., DAI W.T., CAO J.J., TIAN L.W., DENG W.J. Spatiotemporal distribution of carbonyl compounds in China. Environmental Pollution, 197, 316, 2015.

23. GUO S.J., CHEN M., HE X.L.,YANG W.W.,TAN J.H. Seasonal and diurnal characteristics of carbonyls in urban air in Qinzhou, China. Aerosol and Air Quality Research, 14 (6), 1653, 2014.

24. GUO S.J., HE X.L., CHEN M., TAN J.H., WANG Y.H. Photochemical production of atmospheric carbonyls in a rural area in southern China. Archives of Environmental Contamination and Toxicology, 66 (4), 594, 2014.

25. PANG X.B., LEE X. Temporal variations of atmospheric carbonyls in urban ambient air and street canyons of a mountainous city in Southwest China. Atmospheric Environment, 44 (17), 2098, 2010.

26. ZHANG Y.J., MU Y.J., LIU J.F., MELLOUKI A. Levels, sources and health risks of carbonyls and BTEX in the ambient air of Beijing, China. Journal of Environmental Sciences, 24 (1), 124, 2012. 
27. HUANG J., FENG Y.L., LI J., XIONG B., FENG J.L., WEN S., SHENG G.Y., FU J.M., WU M.H. Characteristics of carbonyl compounds in ambient air of Shanghai, China. Journal of Atmospheric Chemistry, 61 (1), 1, 2008.

28. LU H.X., CAI Q.Y., WEN S., CHI Y.G., GUO S.J., SHENG G.Y., FU J.M. Seasonal and diurnal variations of carbonyl compounds in the urban atmosphere of Guangzhou, China. Science of the Total Environment, 408 (17), 3523, 2010.

29. GUO S.J., CHEN M. ${ }^{13} \mathrm{C}$ isotope evidence for photochemical production of atmospheric formaldehyde, acetaldehyde, and acetone pollutants in Guangzhou. Environmental Chemistry Letters, 11 (1), 77, 2013.

30. GUO S.J., WEN S., WANG X.M., SHENG G.Y., FU J.M., HU P., YU Y.X. Carbon isotope analysis for source identification of atmospheric formaldehyde and acetaldehyde in Dinghushan Biosphere Reserve in South China. Atmospheric Environment, 43 (22-23), 3489, 2009.

31. SHEPSON P.B., HASTIE D.R., SCHIFF H.I., POLIZZI M., BOTTENHEIM J.W., ANLAUF K., MACKAY G.I., KARECKI D.R. Atmospheric concentrations and temporal variations of $\mathrm{C}_{1}-\mathrm{C}_{3}$ carbonyl compounds at two rural sites in central Ontario. Atmospheric Environment Part A-General Topics, 25 (9), 2001, 1991.

32. CERON R.M., CERON J.G., MURIEL M. Diurnal and seasonal trends in carbonyl levels in a semi-urban coastal site in the Gulf of Campeche, Mexico. Atmospheric Environment, 41 (1), 63, 2007.

33. ALTEMOSE B., GONG J.C., ZHU T., HU M., ZHANG L., CHENG H., ZHANG L.W., TONG J., KIPEN H.M., OHMAN-STRICKLAND P., MENG Q.Y., ROBSON
M.G., ZHANG J.F. Aldehydes in relation to air pollution sources: A case study around the Beijing Olympics. Atmos Environ, 109, 61, 2015.

34. CHENG Y., LEE S.C., HUANG Y., HO K.F., HO S.S.H., YAU P.S., LOUIE P.K.K., ZHANG R.J. Diurnal and seasonal trends of carbonyl compounds in roadside, urban, and suburban environment of Hong Kong. Atmospheric Environment, 89, 43, 2014.

35. JIANG Z.H., WANGY.J., ZHENGX., LIU X.Z, XIA C.B., XIAO X.Q., LI S. Variation characteristics of atmospheric carbonyl compounds in Zhangjiajie Forest. Research of Environmental Sciences, 29 (9), 1272, 2016 [In Chinese].

36. ATKINSON R., AREY J. Atmospheric degradation of volatile organic compounds. Chemical Reviews, 103 (12), 4605, 2003.

37. LI Y., SHAO M., LU S.H., CHANG C.C., DASGUPTA P.K. Variations and sources of ambient formaldehyde for the 2008 Beijing Olympic games. Atmospheric Environment, 44 (21-22), 2632, 2010.

38. CARTER W.P.L. Development of reactivity scales for volatile organic compounds. Journal of the Air\&Waste Management Association, 44 (7), 881, 1994.

39. DUAN J.C., TAN J.H., YANG L., WU S., HAO J.M. Concentration, sources and ozone formation potential of volatile organic compounds (VOCs) during ozone episode in Beijing. Atmospheric Research, 88 (1), 25, 2008.

40. CARTER W.P.L. Updated maximum incremental reactivity scale and hydrocarbon bin reactivities for regulatory applications. California Air Resources Board Contract 07-339, 2010. 